\title{
Termoterapia na qualidade fisiológica e sanitária de sementes armazenadas de pinhão-manso
}

\section{Thermotherapy on physiological and health quality of stored Jatropha seeds}

\author{
Cristina Fernanda Schneider ${ }^{1 *}$; Fabiane Cristina Gusatto ${ }^{2}$; \\ Marlene de Matos Malavasi ${ }^{3}$; José Renato Stangarlin³; Ubirajara Contro Malavasi ${ }^{3}$
}

\section{Resumo}

\begin{abstract}
Dentre as várias espécies que podem ser utilizadas na obtenção de óleos vegetais para fins energéticos, o pinhão-manso tem sido considerado uma das melhores opções. Para isso, se faz necessário ter sementes de boa qualidade fisiológica e sanitária para um adequado estabelecimento das plantas no campo. $\mathrm{O}$ presente trabalho teve por objetivo avaliar a eficiência do tratamento térmico no controle de patógenos, de campo e de armazenamento, em sementes de pinhão-manso armazenadas. O delineamento experimental foi inteiramente casualizado em esquema fatorial $5 \times 4$ (cinco períodos de armazenamento $\mathrm{x}$ quatro temperaturas de tratamento). As sementes de pinhão-manso, coletadas no município de Dourados - MS, foram submetidas ao beneficiamento e secagem ao sol, em seguida foram armazenadas em câmara seca em embalagem de vidro com tampa de rosca e capacidade de $500 \mathrm{ml}$, pelos períodos de $0,90,180,270$ e 360 dias. Após cada período de armazenamento, as sementes foram submetidas à termoterapia por imersão em água nas temperaturas de $45^{\circ} \mathrm{C}, 50^{\circ} \mathrm{Ce} 55^{\circ} \mathrm{C}$ por 15 minutos; a testemunha foi imersa em água em temperatura ambiente $\left(25 \pm 2^{\circ} \mathrm{C}\right)$ por 15 minutos. Os parâmetros avaliados foram: grau de umidade, germinação, índice de velocidade de germinação, condutividade elétrica e sanidade. $\mathrm{O}$ tratamento térmico nas temperaturas de $45^{\circ} \mathrm{C}, 50^{\circ} \mathrm{C}$ e $55^{\circ} \mathrm{C}$ não foi prejudicial para a germinação e integridade das membranas celulares das sementes. Após 180 dias de armazenamento, a utilização da termoterapia contribui para a conservação do vigor das sementes. Os fungos Penicillium sp. e Acremonium sp. são controlados pela termoterapia nas temperaturas de $45^{\circ} \mathrm{C}, 50^{\circ} \mathrm{C}$ e $55^{\circ} \mathrm{C}$; e Aspergillus sp. é controlado pela temperatura de $55^{\circ} \mathrm{C}$ nos períodos de armazenamento de 180 e 270 dias.
\end{abstract}

Palavras-chave: Jatropha curcas L, germinação, tratamento térmico, sanidade

\begin{abstract}
Among the many species that can be used to obtain vegetable oil for energy, Jatropha is considered one of the best options. Therefore, it is necessary to have seeds with good physiological and health quality in order to have a good establishment of plants in the field. This study aimed to evaluate the efficiency of heat treatment to the control of seed-borne pathogens in stored Jatropha seeds. The experimental design was completely randomized with a factorial $5 \times 4$ (five periods of storage $\mathrm{x}$ four treatment temperatures). The seeds of Jatropha were collected in Dourados - MS, and were subjected to processing and sun drying, and then stored in a dry chamber in glass flaskswith a screw cap and a capacity of $500 \mathrm{~mL}$, for periods
\end{abstract}

\footnotetext{
${ }^{1}$ Eng $^{\text {a }}$ Agra ${ }^{\text {a }}$ Discente do Curso de Doutorado do Programa de Pós-Graduação em Agronomia, Produção Vegetal, Universidade Estadual do Oeste do Paraná, UNIOESTE, Marechal Cândido Rondon, PR. E-mail: tina.schneider@hotmail.com

2 Bióloga, Discente do Curso de Doutorado do Programa de Pós-Graduação em Agronomia, Produção Vegetal, UNIOESTE, Marechal Cândido Rondon, PR. E-mail: fabi_cristina12@hotmail.com

3 Profs. do Programa de Pós Graduação em Agronomia, UNIOESTE, Marechal Cândido Rondon, PR. E-mail: marlenemalavasi@, yahoo.com.br; jose.stangarlin@unioeste.br; biramalavasi@yahoo.com.br

* Autor para correspondência
} 
of $0,90,180,270$, and 360 days. After each storage period, seeds were subjected to thermotherapy by immersion in hot water at temperatures of $45^{\circ} \mathrm{C}, 50^{\circ} \mathrm{C}$, and $55^{\circ} \mathrm{C}$ for 15 minutes; the control treatment was immersed in water at room temperature $\left(25 \pm 2^{\circ} \mathrm{C}\right)$ for 15 minutes. The parameters evaluated were: moisture content, germinations, germination speed index, electrical conductivity and health. Heat treatment at temperatures of $45^{\circ} \mathrm{C}, 50^{\circ} \mathrm{C}$ and $55^{\circ} \mathrm{C}$ don't affect germination and the cell membrane integrity of the seed. After 180 days the use of thermotherapy contributed to the conservation of seed vigor. The fungus Penicillium sp. and Acremonium sp. are eliminated by thermotherapy at temperatures of $45^{\circ} \mathrm{C}, 50^{\circ} \mathrm{C}$ and $55^{\circ} \mathrm{C}$, and Aspergillus sp. is controlled at a temperature of $55^{\circ} \mathrm{C}$ in periods of storage of 180 and 270 days.

Key words: Jatropha curcas L, germination, heat treatment, health

\section{Introdução}

O pinhão-manso (Jatropha curcas L.) oleaginosa da família das Euphorbiaceae apresenta-se como opção agrícola para regiões áridas, semi-áridas e na recuperação de áreas degradadas, através de sua produção e como suprimento de energia (SATO et al., 2009). A espécie desperta interesses para a produção de biodiesel, pois o óleo presente em suas sementes possui todas as características necessárias para a utilização como combustível. Segundo Teixeira (2005), a produção média de frutos em cultivos comerciais chega a $5 \mathrm{t} \mathrm{ha}^{-1}$.

O uso de sementes com qualidade torna-se requisito principal para que a espécie possa ser utilizada no estabelecimento da cultura no campo (MARCOS FILHO, 2005; OLIVEIRA et al., 2014). Os tratamentos sanitários muitas vezes são indispensáveis, pois visam à eliminação de patógenos de campo e de armazenamento presentes nas sementes e que possam comprometer sua germinação e vigor.

Normalmente são realizados tratamentos químicos em frutos e sementes. Contudo, tratamentos físicos como a termoterapia também são eficientes na erradicação de patógenos e podem constituir-se em alternativa para o controle dos mesmos em sementes de pinhão-manso. Entretanto, (MACHADO, 2000; PARISI; SANTOS; MENTEN, 2011) são necessários estudos com relação ao efeito das temperaturas de exposição, sobre a qualidade fisiológica da semente e o controle dos patógenos.

Vários trabalhos vêm mostrando a eficiência da termoterapia, através da imersão das sementes em água quente. Marroni et al. (2009) testaram a termoterapia em sementes de Ricinus communis $\mathrm{L}$. submetendo-as a temperaturas de $45^{\circ} \mathrm{C}$ a $60^{\circ} \mathrm{C}$ em intervalos de 15 e 30 minutos, e verificaram que a incidência de patógenos diminuiu e a qualidade fisiológica da semente não foi prejudicada. Assim como, Vieira (2009), trabalhando com sementes de café, verificou que a termoterapia nas temperaturas de $50^{\circ} \mathrm{C}$ e $60^{\circ} \mathrm{C}$ nos tempos de 1 minuto, 7 minutos, 30 segundos e 15 minutos foi eficiente na redução da incidência de Colletotrichum gloeosporioides, porém, a temperatura de $60^{\circ} \mathrm{C}$ por 15 minutos foi prejudicial para a germinação das sementes.

A qualidade das sementes é determinada por fatores genéticos, físicos, fisiológicos e sanitários, os quais interferem diretamente no potencial de desempenho de campo e durante o armazenamento. (MARCOS FILHO, 2005).

O armazenamento tem como objetivo básico manter o nível de qualidade fisiológica das sementes até sua utilização na semeadura (CARVALHO; NAKAGAWA, 2012). A qualidade das sementes não pode ser melhorada durante o armazenamento, mas pode ser preservada quando as condições de conservação são favoráveis (SANTOS; MENEZES; VILELLA, 2005). Sendo que, durante o armazenamento a umidade relativa do ar e a temperatura influenciam a atividade de fungos do armazenamento. Com isso, a perda da viabilidade das sementes em climas muito úmidos (tropical e subtropical) durante o armazenamento, deve-se, principalmente, a mudanças fisiológicas 
na semente e, em segundo plano, à atividade dos fungos (DHINGRA, 2005; LABEÉ, 2012).

Com isso, em situações em que as condições de armazenamento são favoráveis ao desenvolvimento de patógenos, torna-se necessária a utilização de um tratamento sanitário. Neste contexto, o presente trabalho objetivou avaliar a eficiência do tratamento térmico no controle de patógenos de campo e de armazenamento e qualidade fisiológica de sementes de pinhão-manso armazenadas.

\section{Material e Métodos}

O experimento foi conduzido nos Laboratórios de Tecnologia de Sementes e de Fitopatologia da Universidade Estadual do Oeste do Paraná (UNIOESTE), campus de Marechal Cândido Rondon - PR. As sementes de pinhão-manso foram coletadas na zona rural do distrito de Itahum, município de Dourados, no Estado do Mato Grosso do Sul. A altitude média do local é 485 metros, com as seguintes coordenadas geográficas: latitude $22^{\circ} 05^{\prime} 45^{\prime} \mathrm{S}$, longitude $55^{\circ} 18^{\prime} 50^{\prime} \mathrm{W}$, enquanto o solo é do tipo Latossolo Vermelho distrófico. A lavoura em que foram colhidos os frutos de pinhãomanso foi implantada em novembro de 2006, e as sementes utilizadas no presente trabalho foram colhidos em junho de 2010.

A colheita e o beneficiamento das sementes foram realizados manualmente, e as sementes foram secadas ao sol (ZONTA et al., 2011), sobre estruturas de madeira com tela a uma temperatura média de $26^{\circ} \mathrm{C}$ e umidade relativa do ar média de $56 \%$, sendo que a noite foram recolhidas para local protegido. A secagem foi de cinco dias, tempo suficiente para que as sementes apresentassem teor de água de aproximadamente $7 \%$.

Os tratamentos realizados basearam-se no período de armazenamento e na temperatura de termoterapia. A embalagem de armazenamento foi de vidro transparente com tampa de rosca e capacidade de $500 \mathrm{~mL}$, a tampa foi vedada com fita adesiva transparente. Os períodos de armazenamento foram de $0,90,120,270$ e 360 dias. As temperaturas de termoterapia foram de $25^{\circ} \mathrm{C}, 45^{\circ} \mathrm{C}, 50^{\circ} \mathrm{C}$ e $55^{\circ} \mathrm{C}$. Para o armazenamento utilizou ambiente controlado com temperatura de $14 \pm 2^{\circ} \mathrm{C}$ e umidade relativa do ar entre 65 e $80 \%$.

Foi determinado o grau de umidade por método gravimétrico, pela diferença de massas após as sementes serem submetidas à estufa com temperatura de $105 \pm 2^{\circ} \mathrm{C}$ por 24 horas (BRASIL, 2009b). Utilizaram-se cinco repetições de duas sementes para cada período de armazenagem, e os resultados foram expressos em porcentagem.

O tratamento térmico foi realizado em todos os períodos de armazenamento por meio de imersão em água quente previamente aquecida em banho-maria. As sementes de pinhão-manso foram colocadas em sacos de filó, e posteriormente imersas em água, nas temperaturas de $25^{\circ} \mathrm{C}, 45^{\circ} \mathrm{C}, 50^{\circ} \mathrm{C}$ e $55^{\circ} \mathrm{C}$ por 15 minutos. As sementes imersas em $25^{\circ} \mathrm{C}$ constituíram a testemunha. Após a termoterapia as sementes foram colocadas para secar em ambiente sombreado e arejado por 24 horas.

A incidência de fungos patogênicos de armazenamento e de campo nas sementes de pinhão manso foi determinada segundo o Manual de Análise Sanitária (BRASIL, 2009a), pelo método do papel filtro com congelamento. As sementes foram distribuídas em placas gerbox ${ }^{\circledR}$, contendo duas folhas de papel mata borrão, embebidas em água destilada, para cada amostra. Após plaqueamento, as sementes foram incubadas em câmara de germinação (BOD) a temperatura de $25^{\circ} \pm 2^{\circ} \mathrm{C}$ durante 24 horas. Em seguida, as sementes foram submetidas ao congelamento de $-18^{\circ} \mathrm{C}$ por 24 horas sendo então reconduzidas à câmara de germinação por mais cinco dias.

$\mathrm{Na}$ avaliação foi determinada a incidência de fungos no tegumento das sementes. As identificações dos fungos foram efetuadas de acordo com as características morfológicas observadas (BARNETT; HUNTER, 1987), empregando-se 
microscópios estereoscópicos e óticos. Os dados foram expressos em porcentagem. Foram utilizadas quatro repetições de 25 sementes por tratamento.

No ensaio de germinação foram utilizadas quatro repetições de 25 sementes para cada tratamento. As sementes foram semeadas entre areia autoclavada a $120^{\circ} \mathrm{C}$ por 20 minutos, em bandejas e colocadas em câmara de germinação à temperatura de $25 \pm 2^{\circ} \mathrm{C}$, com fotoperíodo de 12 horas. As contagens foram diárias para a avaliação da germinação das sementes durante o período de 20 dias. Considerou-se semente germinada quando a plântula emergiu e os cotilédones ultrapassaram a superfície do substrato e abriram. A partir desses dados calculou-se a porcentagem de germinação.

Simultaneamente ao teste de germinação foi determinado o índice de velocidade de germinação (IVG) conforme metodologia descrita por Maguire (1962).

A condutividade elétrica foi definida a partir de quatro repetições de 20 sementes por tratamento, sendo estas previamente pesadas em balança analítica de precisão de 0,0001 g. Posteriormente as sementes foram imersas em $75 \mathrm{ml}$ de água deionizada em copos plásticos de $300 \mathrm{~mL}$. Em seguida acondicionadas e mantidas em câmara de germinação do tipo BOD, em temperatura de $25^{\circ} \mathrm{C} \pm 2{ }^{\circ} \mathrm{C}$, por um período de 12 horas no escuro (BRAGA, 2010). A leitura foi realizada com condutivímetro e os resultados expressos em $\mu \mathrm{mho}$ $\mathrm{cm}^{-1} \mathrm{~g}^{-1}$.

O delineamento adotado foi o inteiramente casualizado, em esquema fatorial $5 \times 4$, constituído de cinco períodos de armazenamento, com quatro temperaturas. Os dados obtidos foram submetidos à análise de variância através do programa Sisvar 5.3 (FERREIRA, 2011), e havendo diferença as médias foram comparadas pelo teste de Tukey $(p \leq 0,05)$.
Após a análise de variância com base no delineamento proposto e verificada a significância do teste $\mathrm{F}$ para as interações em todas as características avaliadas, foi realizado o ajuste de superfícies de resposta destas características em função do período de armazenamento e da temperatura de termoterapia.

A análise de regressão múltipla polinomial foi realizada utilizando-se como variáveis dependentes: início da germinação, final da germinação, índice de velocidade de germinação e condutividade elétrica. Para a escolha do modelo de melhor ajuste foi utilizado como critério o valor mais elevado de $\mathrm{R}^{2}$, sendo que o modelo utilizado foi: $\mathrm{Z}+\mathrm{a}+\mathrm{b} \mathrm{X}+$ $c X^{2}+d Y+e Y^{2}+f X Y+\epsilon$, onde $Z=$ variável dependente, $\mathrm{X}=$ temperatura de termoterapia, $\mathrm{Y}=$ período de armazenamento das sementes $\epsilon=$ erro.

Para estimar as superfícies de resposta foram ajustados os modelos escolhidos pelo maior valor de $\mathrm{R}^{2}$ com base nas médias dos tratamentos. Cada componente do modelo foi testado ate $5 \%$ de probabilidade, pelo teste $\mathrm{F}$, utilizando-se o aplicativo computacional Statistica Versão 6.0 (CALADO; MONTGOMERY, 2003).

\section{Resultados e Discussão}

Os valores de grau de umidade apresentaram diferença entre os períodos de armazenamento (Figura 1). O maior grau de umidade foi encontrado no período de armazenamento de 180 dias sendo de $9,3 \%$, e as sementes armazenadas a 0 dias apresentaram o menor grau de umidade $(8,1 \%)$. Aos 180 dias de armazenamento o grau de umidade aumentou 1,2\% comparado ao 0 dia de armazenamento. Aos 360 dias de armazenamento o grau de umidade foi de $8,5 \%$, ou seja, diminuiu $0,8 \%$ comparado aos 180 dias. Essa variação no grau de umidade influenciou resultados de germinação, porém, o mesmo não foi observado para os resultados de sanidade. 
Figura 1. Análise de regressão para o grau de umidade (\%) em sementes de pinhão-manso provenientes de diferentes períodos de armazenamento (dias).

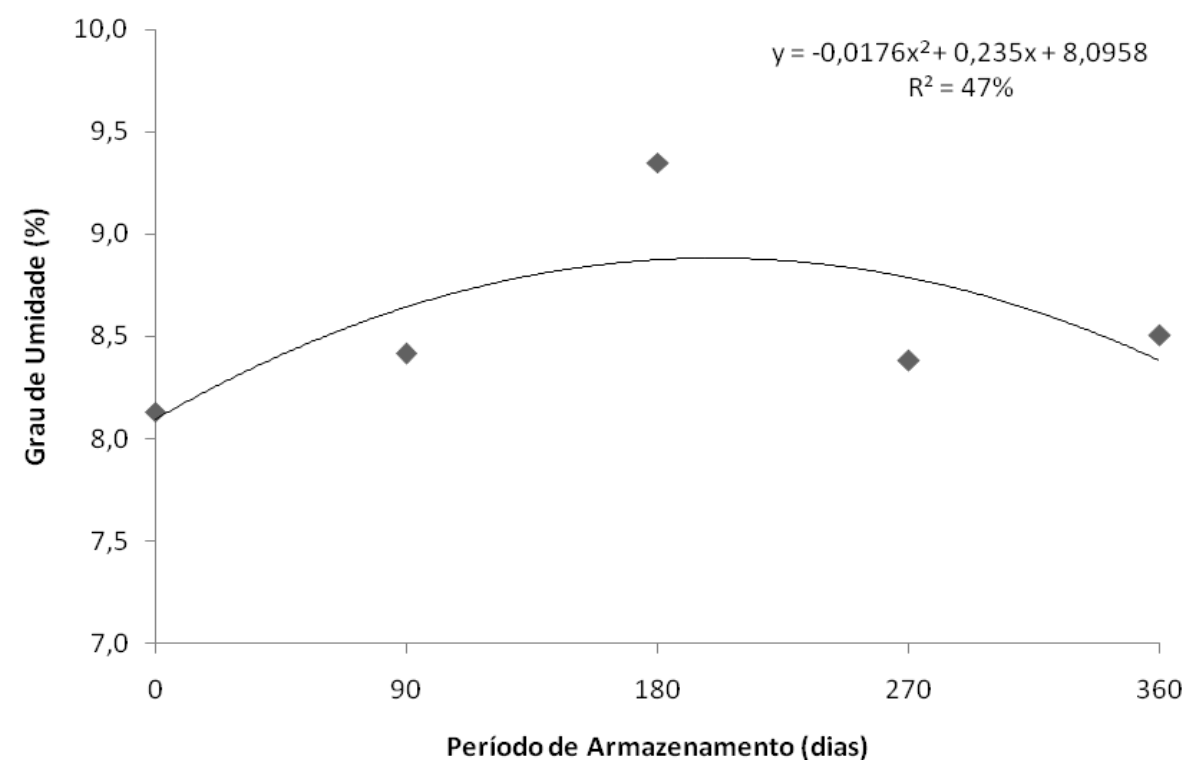

Fonte: Elaboração dos autores.

Na comparação dos valores de germinação foi verificado que nenhum dos tratamentos inviabilizou a germinação das sementes. A germinação não apresentou efeito significativo $(\mathrm{P}>0,05)$ em função da interação entre as temperaturas de termoterapia e os períodos de armazenamento, ocorrendo aumento na porcentagem de germinação ao longo do período, com redução aos 270 dias e aumento aos 360 dias de avaliação (Figura 2). De 0 a 90 dias a germinação foi de 66 e $68 \%$, respectivamente, aos 180 a 270 dias as porcentagens de germinação foram de 85 e $61 \%$, respectivamente, e aos 360 dias a porcentagem foi de $80 \%$. Verificou-se diminuição de $24 \%$ da germinação aos 270 dias em relação aos 180 dias, sendo que, aos 360 dias a germinação aumentou 19\% em relação aos 180 dias.

Essa flutuação nos resultados da porcentagem de germinação pode ter relação com o grau de umidade das sementes, pois aos 180 dias de armazenamento obteve-se maior porcentagem de germinação e nesse mesmo período obteve-se maior grau de umidade, ao passo que, sementes com menor grau de umidade apresentaram menor porcentagem de germinação. Esse resultado pode ser explicado devido ao fato de que sementes muito secas quando reativam o processo de germinação, podem sofrer danos irreversíveis pela rápida embebição, devido a grande diferença de potenciais hídricos, com isso, pode ocorrer a perda da integridade das membranas celulares e desnaturação de proteínas (MARCOS FILHO, 2005).

Os valores de germinação total obtidos por Höring, Malavasi e Malavasi (2010) em sementes de Jatropha curcas L. armazenadas em sacos de papelão empilhados sobre estrado de madeira em ambiente sombreado não controlado, no período de 17 e 164 dias de armazenamento, foram de 72 e $55 \%$, respectivamente, sendo que no presente trabalho obteve-se porcentagem inferior no período inicial, em contrapartida no maior período obtevese maior germinação. 
Figura 2. Germinação (\%) em função do período de armazenamento (dias) em sementes de pinhão-manso.

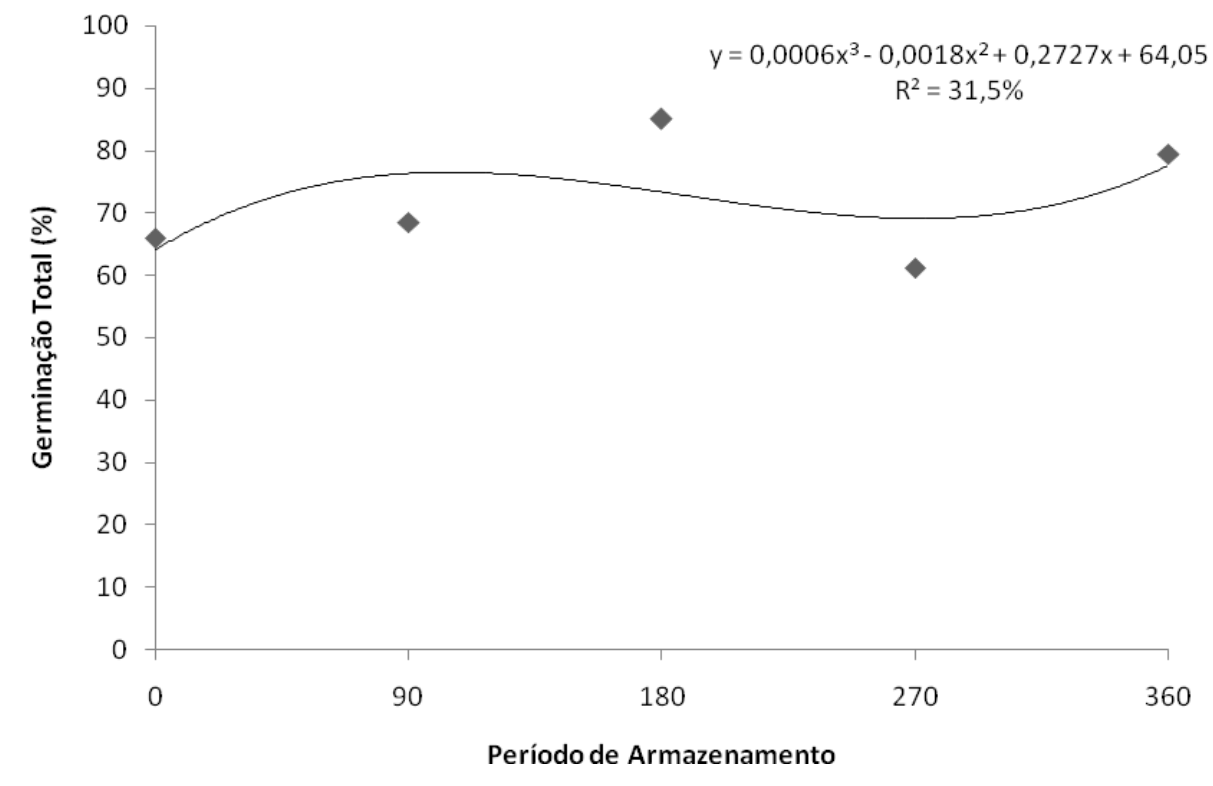

Fonte: Elaboração dos autores.

Para o índice de velocidade de germinação (IVG) foi verificado que à medida que foi aumentada a temperatura de termoterapia, os valores de IVG diminuíram nos menores períodos de armazenamento, em contrapartida, nos maiores períodos de armazenamento obteve-se menor IVG nas menores temperaturas (Figura 3). O IVG foi maior na temperatura de $25^{\circ} \mathrm{C}$ nos períodos de 0 a 180 dias, apresentando índice superior a 2,2. O menor índice foi obtido nas temperaturas de $50^{\circ} \mathrm{C}$ a $55^{\circ} \mathrm{C}$ e $25^{\circ} \mathrm{C}$ nos períodos de 0 a 180 dias e 270 a 360 dias, respectivamente, com índice inferior a 2.

Avaliando-se o vigor das sementes pela velocidade de germinação, foi possível verificar que as sementes submetidas ao armazenamento até 180 dias sem o tratamento térmico mantiveram o vigor.

Matheus e Lopes (2007) constataram que o aumento da permanência de sementes de
Schyzolobium parahyba na água em ebulição resultou na redução da porcentagem de germinação e do IVG, provavelmente devido a danos sofridos pelo embrião em virtude da exposição mais prolongada à água com a temperatura muito elevada. Semelhante aos resultados obtidos nesse estudo, em que quanto maior a temperatura do tratamento para sementes armazenadas por 0 a 180 dias, menor foi o IVG.

Segundo Machado (2000), a termoterapia é mais danosa ao vigor na medida em que a semente apresenta qualidade fisiológica inferior. Sementes mais vigorosas são mais tolerantes a altas temperaturas em comparação as sementes com vigor comprometido. $\mathrm{O}$ mesmo pode ser observado no presente estudo, em que, sementes que apresentaram baixas porcentagens de germinação (armazenadas por 0 e 90 dias, 66 e $68 \%$, respectivamente) e submetidas a altas temperaturas de termoterapia $\left(50^{\circ} \mathrm{C}\right.$ a $\left.55^{\circ} \mathrm{C}\right)$ apresentaram baixo IVG, inferior a 2 . 
Figura 3. Superfície de resposta do índice de velocidade de germinação (IVG), de acordo com a temperatura de termoterapia $\left({ }^{\circ} \mathrm{C}\right)$ e período de armazenamento (dias) das sementes de pinhão-manso.

$$
\text { IVE }=1,8989-0,0018 x+0,0305 y-0,0000009693 x^{2}+0,0000063606 x y-0,0006 y^{2} \quad R^{2}=0,60^{\star *}
$$

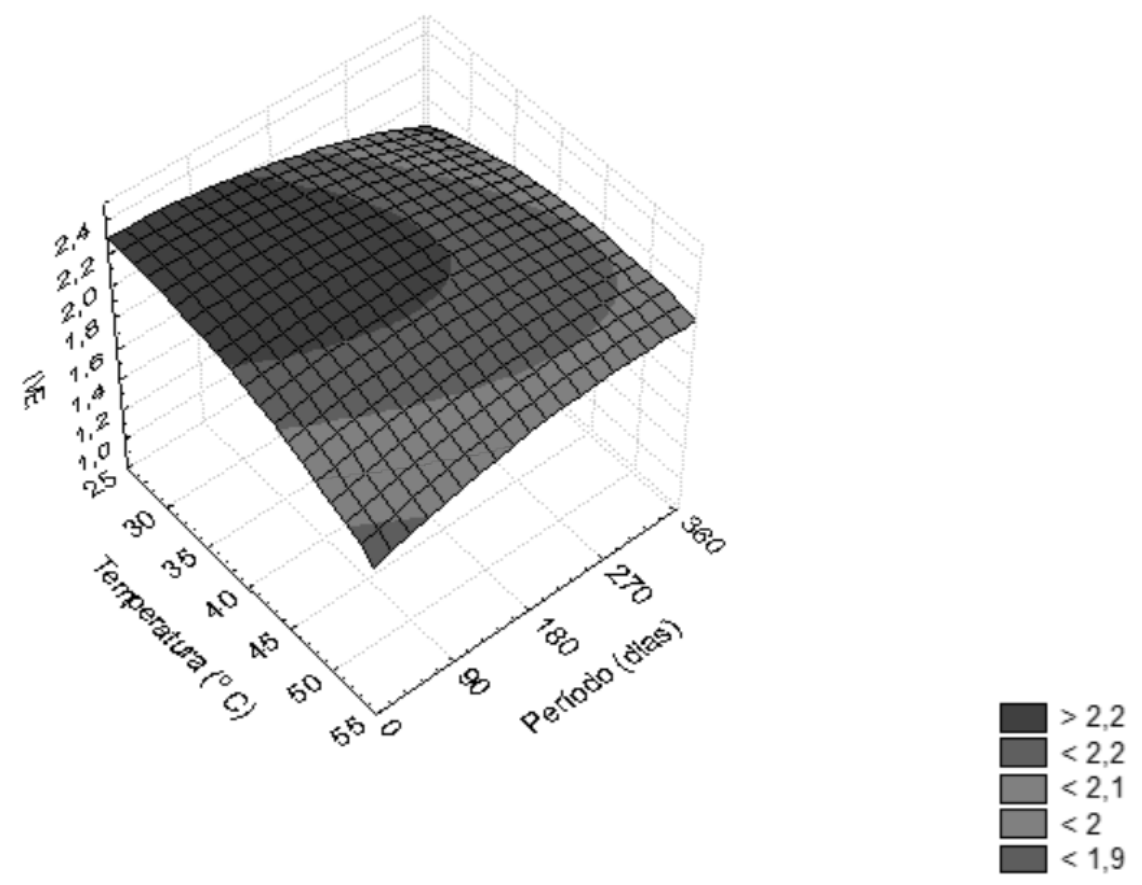

Fonte: Elaboração dos autores.

Pelo teste de condutividade elétrica (Figura 4), que avalia a integridade das membranas celulares das sementes, foi possível evidenciar para os períodos de 0 a 180 dias e para todas as temperaturas, que este parâmetro foi inferior a $60 \mu \mathrm{mho} \mathrm{cm}^{-1}$ $\mathrm{g}^{-1}$. No período de 360 dias na temperatura de $25^{\circ} \mathrm{C}$ ocorreu aumento da condutividade elétrica, apresentando valores superiores a $75 \mu \mathrm{mho} \mathrm{cm}^{-1} \mathrm{~g}^{-1}$, o que permite observar que os tratamentos térmicos não contribuíram para a perda da integridade das membranas celulares.

A perda de lixiviados inclui açúcares, aminoácidos, ácidos graxos, proteínas, enzimas e íons inorgânicos. Sob condições de campo, essa liberação após a semeadura, além de provocar a perda da compartimentalização celular, estimula o crescimento de microorganismos nocivos à emergência das plântulas (MARCOS FILHO, 2005). Com isso, pode-se afirmar que a termoterapia mesmo em altas temperaturas e, aplicada em sementes armazenadas por maiores períodos que, consequentemente, apresentaram maior grau de deterioração, não serão prejudicadas quanto a lixiviação de solutos.

Resultado contrário aos obtidos neste trabalho foram encontrados por Coutinho et al. (2007), que obtiveram aumento da condutividade elétrica de sementes de Zea mays (perda de vigor), com o aumento do tempo de tratamento térmico, observada principalmente nos tempos de 10 a 20 min a uma temperatura de $60^{\circ} \mathrm{C}$. 
Figura 4. Superfície de resposta da condutividade elétrica $\left(\mu \mathrm{mho} \mathrm{cm}^{-1} \mathrm{~g}^{-1}\right)$, de acordo com a temperatura de termoterapia $\left({ }^{\circ} \mathrm{C}\right)$ e período de armazenamento (dias), para sementes de pinhão-manso.

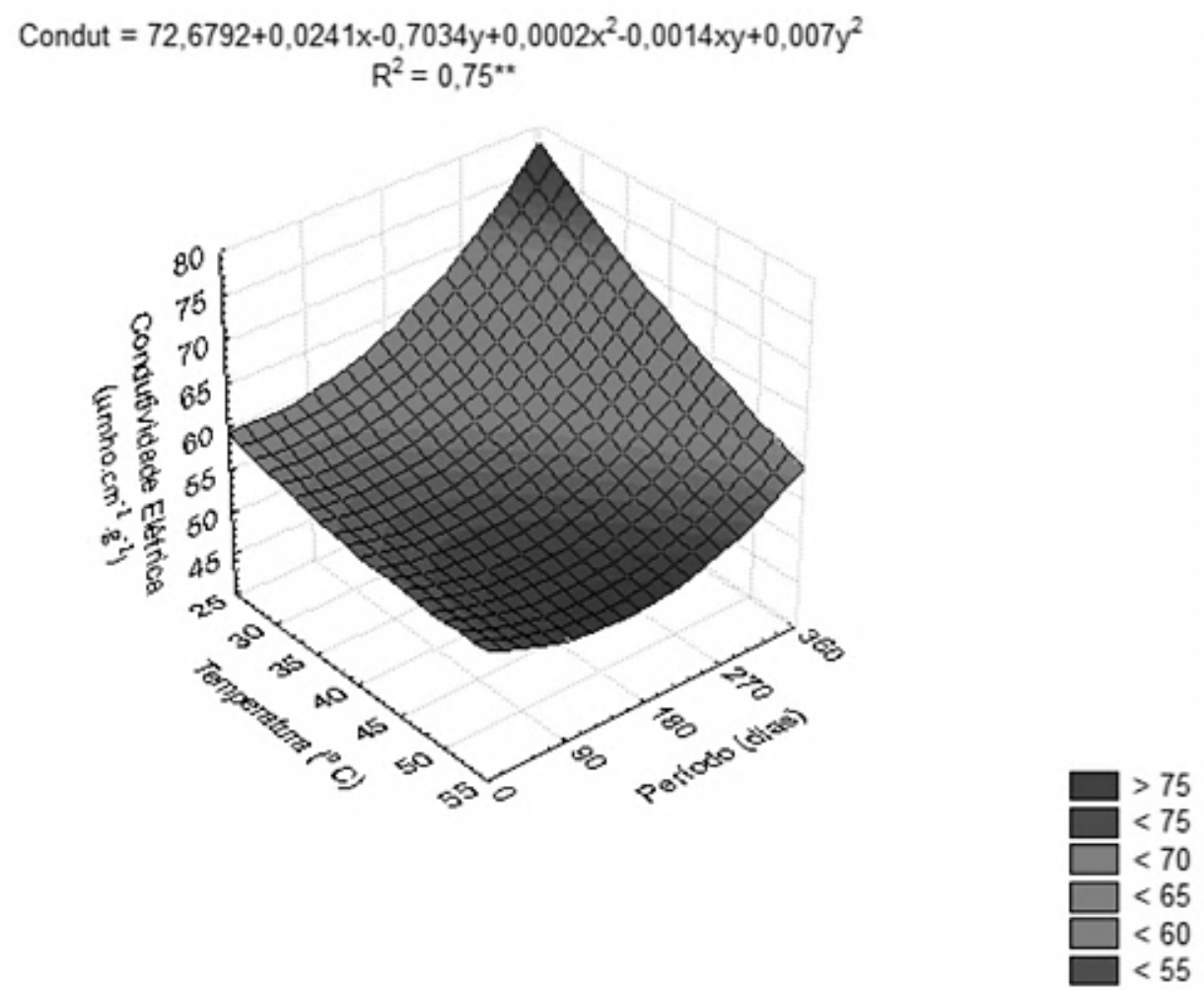

Fonte: Elaboração dos autores.

$\mathrm{Na}$ avaliação da sanidade das sementes de Jatropha curcas L. foram detectados os fungos: Fusarium sp., Aspergillus sp., Penicillium sp. e Acremonium sp. (Tabela 1). Na testemunha os fungos Penicillium sp. e Acremonium sp. incidiram até os períodos de 0 e 180 dias de armazenamento, respectivamente. Ao longo dos períodos de armazenamento Aspergillus sp. não apresentou incidência e Fusarium sp. não foi controlado.

Nos tratamentos térmicos os fungos Penicillium sp. e Acremonium sp. foram controlados. Resultados similares foram encontrados por Braga et al. (2010), em sementes de tomate.

O fungo Aspergillus sp. praticamente manteve o mesmo valor de incidência nos tratamentos térmicos, apenas na temperatura de $55^{\circ} \mathrm{C}$ nos períodos de 180 e 270 dias de armazenamento foi controlado.
Tanto a presença de Aspergillus sp. como de Penicillium sp. depreciam a qualidade das sementes por reduzirem o poder germinativo, alterarem a coloração e contribuírem para a deterioração das sementes (MACHADO, 2000). O mesmo pode ser constatado no presente trabalho, pois a incidência de Aspergillus sp. pode ter contribuído para diminuir o IVG das sementes, visto que, a maior velocidade de germinação foi constatada nas sementes que não apresentaram incidência deste fungo.

O fungo Fusarium sp. não foi controlado nos tratamentos térmicos, por outro lado, Mendes et al. (2001) observaram que sementes de alfafa submetidas a tratamento térmico seco de $60^{\circ} \mathrm{C}$ e $90^{\circ} \mathrm{C}$ não apresentaram desenvolvimento de Fusarium oxysporum. 
Tabela 1. Incidência de fungos (\%) em sementes de pinhão-manso provenientes de diferentes períodos de armazenamento (dias) e tratadas por termoterapia.

\begin{tabular}{|c|c|c|c|c|c|}
\hline \multirow{2}{*}{$\begin{array}{c}\text { PERÍODO DE } \\
\text { ARMAZENAMENTO } \\
\text { (DIAS) }\end{array}$} & \multirow[b]{2}{*}{ FUNGOS } & \multicolumn{4}{|c|}{ TEMPERATURA $\left({ }^{\circ} \mathrm{C}\right)$} \\
\hline & & 25 & 45 & 50 & 55 \\
\hline \multirow{4}{*}{$\mathbf{0}$} & Fusarium sp. & 100 & 100 & 100 & 100 \\
\hline & Aspergillus sp. & 0 & 6 & 9 & 12 \\
\hline & Penicillium sp. & 1 & 0 & 0 & 0 \\
\hline & Acremonium sp. & 11 & 0 & 0 & 0 \\
\hline \multirow{4}{*}{90} & Fusarium sp. & 94 & 85 & 99 & 100 \\
\hline & Aspergillus sp. & 0 & 1 & 10 & 5 \\
\hline & Penicillium sp. & 0 & 0 & 0 & 0 \\
\hline & Acremonium sp. & 4 & 0 & 0 & 0 \\
\hline \multirow{4}{*}{180} & Fusarium sp. & 96 & 99 & 100 & 100 \\
\hline & Aspergillus sp. & 0 & 7 & 4 & 0 \\
\hline & Penicillium sp. & 0 & 0 & 0 & 0 \\
\hline & Acremonium sp. & 1 & 0 & 0 & 0 \\
\hline \multirow{4}{*}{270} & Fusarium sp. & 79 & 87 & 100 & 100 \\
\hline & Aspergillus sp. & 0 & 5 & 3 & 0 \\
\hline & Penicillium sp. & 0 & 0 & 0 & 0 \\
\hline & Acremonium sp. & 0 & 0 & 0 & 0 \\
\hline \multirow{4}{*}{360} & Fusarium sp. & 87 & 100 & 100 & 100 \\
\hline & Aspergillus sp. & 0 & 10 & 5 & 2 \\
\hline & Penicillium sp. & 0 & 0 & 0 & 0 \\
\hline & Acremonium sp. & 0 & 0 & 0 & 0 \\
\hline
\end{tabular}

Fonte: Elaboração dos autores.

\section{Conclusão}

Para sementes de pinhão-manso armazenadas em embalagem de vidro transparente as temperaturas de $45^{\circ} \mathrm{C}, 50^{\circ} \mathrm{C}$ e $55^{\circ} \mathrm{C}$ utilizadas na termoterapia não prejudicaram a germinação e a integridade das membranas celulares das sementes. Nas sementes armazenadas após 180 dias a utilização da termoterapia contribuiu para a conservação do vigor das sementes. Os fungos Penicillium sp. e Acremonium sp. foram controlados pela termoterapia nas temperaturas de $45^{\circ} \mathrm{C}, 50^{\circ} \mathrm{C}$ e $55^{\circ} \mathrm{C}$. O fungo Aspergillus sp. foi controlado pela temperatura de $55^{\circ} \mathrm{C}$ nos períodos de armazenamento de 180 e 270 dias.

\section{Agradecimentos}

A Capes, pela concessão da bolsa de estudos.

\section{Referências}

BARNETT, H. L.; HUNTER, B. B. Ilustrated genera of imperfect fungi. 4. ed. New York: Macmillan, 1987. 218 p.

BRASIL. Ministério da Agricultura Pecuária e Abastecimento. Manual de análise sanitária de sementes. Brasília: MAPA/ACS, 2009a. 2000 p.

Ministério da Agricultura, Pecuária e Abastecimento. Regras para análise de sementes. Brasília: MAPA/ACS, 2009b. 395 p.

BRAGA, M. P.; OLINDA, R. A.; HOMMA, S. K.; DIAS, C. T. S. Relações entre tratamento térmico, germinação, vigor e sanidade de sementes de tomate. Revista Brasileira de Sementes, Londrina, v. 32, n. 1, p. 101-110, 2010.

BRAGA, N. S. Avaliação fisiológica de sementes de pinhão manso. 2010. Dissertação (Mestrado em Fitotecnia) - Universidade Federal Rural do Rio de Janeiro, Seropédica. 
CALADO, V.; MONTGOMERY, D. Planejamento de experimentos usando o Statistica. Rio de Janeiro: E-Papers Serviços Editoriais, 2003. 260 p.

CARVALHO, N. M.; NAKAGAWA, J. (Ed.). Sementes: ciência, tecnologia e produção. Jaboticabal: FUNEP, 2012. 590 p.

COUTINHO, M. C.; SILVA-MANN, R.; VIEIRA, M. G. G. C.; MACHADO, C. F.; MACHADO, J. C. Qualidade sanitária e fisiológica de sementes de milho submetidas a termoterapia e condicionamento fisiológico. Fitopatologia Brasileira, Brasília, v. 32, n. 6, p. 458-464, nov./dez. 2007.

DHINGRA, O. D. Teoria da transmissão de patógenos fúngicos por sementes. In: ZAMBOLIM, L. Sementes: qualidade fitossanitária. Viçosa: UFV; DFP, 2005. p. 75112.

FERREIRA, D. F. Sisvar: a computer statistical analysis system. Ciência e Agrotencologia, Lavras, v. 35, n. 6, p. 1039-1042, 2011.

HÖRING, C. F.; MALAVASI, M. M.; MALAVASI, U. C. Armazenamento não controlado na qualidade de sementes de Jatropha curcas L. Semina: Ciências Agrárias, Londrina, v. 32, n. 2, p. 521-526, abr./jun. 2010.

LABEÉ, L. M. B. Armazenamento de sementes. In: PESKE, S. T.; VILELLA, F. A.; MENEGHELLO, G. E. Sementes: fundamentos científicos e tecnológicos. Pelotas: Editora Universitária UFPel, 2012. p. 482-828.

MAGUIRE, J. D. Speeds of germination-aid selection emergence and vigor. Crop Science, Madison, v. 2, n. 1, p. 176-7, 1962.

MACHADO, J. C. Tratamento de sementes no controle de doenças. Lavras: UFLA, 2000. 138 p.

MARCOS FILHO, J. Fisiologia de sementes de plantas cultivadas. Piracicaba: FEALQ, 2005. 495 p.

MARRONI, I. V.; ZANATTA, Z. G. C. N.; CASAGRANDE JUNIOR, J. G.; UENO, B. MOURA, A. B. Efeito do tratamento com calor seco e água quente sobre a germinação e controle de microrganismos associados às sementes de mamoneira. Arquivos do Instituto Biológico, São Paulo, v. 76, n. 4, p. 461-467, out./dez. 2009.
MATHEUS, M. T.; LOPES, J. C. Termoterapia em sementes de guapuruvú (Schyzolobium parahyba (Vell.) Blake). Revista Brasileira de Biociências, Porto Alegre, v. 5, p. 330-332, jul. 2007. Suplemento 2.

MENDES, M. S. S.; LIMA, P. M. M. P.; FONSECA, J. N. L.; SANTOS, M. de F. Erradicação de Fusarium oxysorum em sementes de alfafa utilizando termo e quimioterapia. Fitopatologia Brasileira, Brasília, v. 30, n. 2, p. 148-152, jun. 2001.

OLIVEIRA, S.; TAVARES, L. C.; LEMES, E. S.; BRUNES, A. P.; DIAS, I. L.; MENEGHELLO, G. E.; Tratamento de sementes de Avena sativa I. com zinco: qualidade fisiológica e desempenho inicial de plantas. Semina: Ciências Agrárias, Londrina, v. 35, n. 6, p. 1131-1142, maio/jun. 2014.

PARISI, J. J.; SANTOS, A.; MENTEN, J. O. M. Tratamento de sementes florestais. In: SANTOS, A. F.; PARISI, J. J. D.; MENTEN, J. O. M. Patologia de sementes florestais. Colombo: Embrapa Florestas, 2011. p. 105-114.

SANTOS, C. M. R.; MENEZES, N. L. de; VILELLA, F. A. Modificações fisiológicas e bioquímicas em sementes de feijão no armazenamento. Revista Brasileira de Sementes, Pelotas, v. 27, n. 1, p. 104-114, jun. 2005.

SATO, M.; BUENO, O. C.; ESPERANCINI, M. S. T.; FRIGO, E. P. A cultura do pinhão-manso (Jatropha curcas L.): uso para fins combustíveis e descrição agronômica. Revista Varia Scientia, Cascavel, v. 7, n. 13, p. 47-62, 2009.

TEIXEIRA, L. C. Potencialidade de oleaginosas para produção de biodiesel. Informe Agropecuário, Belo Horizonte, v. 26, n. 229, p. 18-27, 2005.

VIEIRA, J. F. Quimioterapia e termoterapia no controle do Colletotrichum gloeosporioides, agente da mancha manteigosa, em cafeeiro (Coffea arabica L.). 2009. Dissertação (Mestrado em Agronomia) - Universidade Federal de Lavras, Lavras.

ZONTA, J. B.; ARAUJO, E. F.; ARAUJO, R. F.; DIAS, L.A. S. Diferentes tipos de secagem: efeitos na qualidade fisiológica de sementes de pinhão manso. Revista Brasileira de Sementes, Londrina, v. 33, n. 4, p. 721-731, 2011. 